\section{Pericardial tamponade: a rare complication of sternal bone marrow biopsy}

\author{
Petr Santavy, Martin Troubil, \\ Vladimir Lonsky
}

Department of Cardiac Surgery, Palacky University Teaching Hospital, Olomouc, Czech Republic

\section{Abstract}

Injury of the heart with concomitant pericardial tamponade as a result of sternal bone marrow biopsy is rare. An 80-year-old man was admitted with dehydration and non-specified abdominal pain to the regional hospital. Sternal aspiration biopsy was performed because of anemia and thrombocytopenia. Later on, because of the back pain, general weakness and blood pressure drop, an echocardiography examination was indicated. Pericardial fluid collection was found. Anticipated ascending aortic dissection was excluded on computed tomography scan, but pericardial fluid collection was confirmed. Transfer to our cardiac surgical facility ensued. Limited heart tamponade was affirmed on echocardiography and surgery was immediately indicated. Blood effusion was found in upper mediastinal fat tissue and $300 \mathrm{~mL}$ of blood were evacuated from opened pericardial space. Stab wound by sternal biopsy needle at the upper part of ascending aorta was repaired by pledgeted suture. Postoperative course was uneventful.

\section{Introduction}

Sternal bone marrow biopsy belongs to invasive diagnostic methods for differential diagnosis of whole spectrum of hematological diseases. As an invasive procedure, minor and major complications are subscribed in literature. Local complications (bleeding and infection from puncture site) are considered as minor ones. Major ones are due to improper technique or instrument usage and are as follows: manubrio-sternal dehiscence, sternal fracture, pneumopericardium, pneumotorax and biopsy needle breakage. Life threatening complications are because of pericardial tamponade caused by ascending aorta or right ventricle injury. We are subscribing such an injury below.

\section{Case Report}

An 80-year-old man was brought to the regional hospital because of unclear abdominal pain, diarrhea and concomitant dehydration. He was admitted with diagnosis of pancreatic irritation and acute enteritis. Later, on the basis of laboratory examination of anemia (Ery $3.77 \times 10^{12} \mathrm{~L}, \mathrm{Hb} 112 \mathrm{~g} / \mathrm{L}$, Hct 0.35 ) and thrombocytopenia $\left(72 \times 10^{9} \mathrm{~L}\right)$, sternal bone marrow aspiration biopsy was performed. Approximately 45 minutes after the procedure the patient was complaining about general weakness and backache. Echocardiography examination showed pericardial effusion. Later, computer tomography scan excluded suspected ascending aortic dissection. Because of slowly ongoing hemodynamic stability deterioration, the patient was transported to cardiac surgical facility. Transoesophageal echocardiography confirmed pericardial tamponade with right atrium and ventricle compression and dyskinesis (Figure 1A). Immediate surgery was indicated.

Before surgical field draping off, puncture site on sternum was clearly visible (Figure 1B). After midline sternotomy, blood effusion in upper mediastinal tissue was found. When pericardial sac was opened, approximately 300 $\mathrm{mL}$ of blood were evacuated and hemodynamic stability was immediately achieved. Stab injury was found on the ascending aorta (Figure 1C). This location was sutured with pericardial pledgets. During postoperative course rehydration and short-time full parenteral nutrition was necessary. Overall state of health gradually improved and the patient was transferred back to regional hospital on $7^{\text {th }}$ post-operative day for further rehabilitation.

\section{Discussion}

Bone marrow examination is used in the diagnosis of a number of hematological conditions. Aspiration may be done at several sites, but sternum is supposed to be the easiest site from which to obtain the most cellular marrow. ${ }^{1}$

Heart injury with pericardial tamponade due to sternal puncture bone marrow biopsy has been rarely subscribed in literature. In 2003 issue of British Journal of Haematology, ${ }^{2}$ group of 54,890 sternal bone marrow biopsies were analyzed. Overall complications were found in 26 cases, bleeding in 14. No case of heart or aortic injury was observed. Authors from Denmark are on the contrary more cautious about heart injury. ${ }^{3}$ They have studied 34 sternal aspiration death-complication cases published and have identified performing
Correspondence: Petr Santavy, Department of Cardiac Surgery, Palacky University Teaching Hospital, I.P.Pavlova 6, 77520 Olomouc, Czech Republic. Tel. +42.058 .585 .2344 .

E-mail: petr.santavy@fnol.cz

Key words: bone marrow biopsy, pericardial tamponade, aortic injury.

Contributions: the authors contributed equally.

Conflict of interests: the authors declare no potential conflict of interests.

Received for publication: 13 May 2013.

Revision received: 8 July 2013

Accepted for publication: 25 July 2013.

This work is licensed under a Creative Commons Attribution NonCommercial 3.0 License (CC BYNC 3.0).

(C) Copyright P. Santavy et al., 2013

Licensee PAGEPress, Italy

Hematology Reports 2013; 5:e13

doi:10.4081/hr.2013.e13
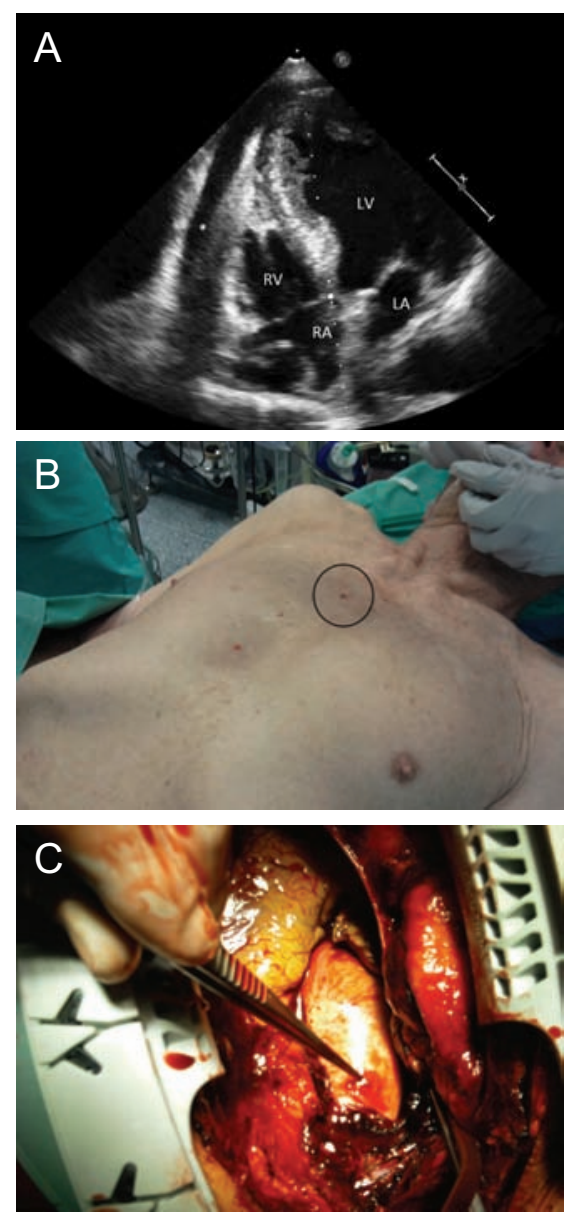

Figure 1. A) Computed tomography scan. $R A$, right atrium; $R V$, right ventricle; $L A$, left atrium; $L V$, left ventricle; asterisk, pericardial effusion. B) Site of bone marrow biopsy puncture (encircled). C) Site of ascending aorta stab injury (showed by forceps). 
physician lack of experience and wrong location of puncture site as a cause of trouble. German authors have published five cases of periprocedural right ventricle injury where one patient only was saved by emergent surgery. ${ }^{4}$ Sternal biopsy peri-procedural death was studied by American authors also. As a main cause of injury they have observed incorrect biopsy needle length according to sternal bone width. ${ }^{5}$ These studies are 10-30 years old and probable reason for late diagnosis of pericardial tamponade was lack of bedside echocardiography examination.

Occasional case reports of sternal biopsy heart injuries were published recently. ${ }^{6,7}$ They are very rare (approx. $0.8 \%$ of all sternal biopsies performed). Adequate diagnostic echocardiography and timely cardiac surgery plays principal role in death complication prevention. ${ }^{8}$ Midline sternotomy and direct suture of injury site is a principle of successful surgical treatment. ${ }^{9}$

\section{Conclusions}

According to aforementioned studies, case reports and our clinical practice, several essential suggestions for sternal bone marrow biopsy arise: i) proper indication, clinical benefit must always outweigh potential risks; ii) experience of performing physician; iii) proper biopsy needle and its length; iv) site of puncture, medial part of sternal manubrium at the level of first intercostal space (should never be performed lower); v) follow up of the patient and timely echocardiography examination in case of any clinical status uncertainty; vi) in case of hemopericardium, fast cardiac surgery is indicated.

\section{References}

1. Knowles S, Hoffbrand AV. Bone marrow aspiration and trephine biopsy. Br Med J 1980;281:204-5.

2. Bain BJ. Bone marrow biopsy morbidity and mortality. Br J Haematol 2003;121:94951.

3. Bichel J. [Serious complications of sternal puncture]. Ugeskr Laeger 1989;151:442-4. [Article in Danish].

4. Püschel K, Mattern R, Mittmeyer HJ,
Schneider V. Errors and hazards: fatalities through sternal punctrue. Dtsch Med Wochenschr 1985;110:1611-3. [Article in German].

5. Pascali VL, Lazzaro P, Fiori A. Is sternal bone marrow needle biopsy still a hazardous technique? Report of three further fatal cases. Am J Forensic Med Pathol 1987;8:42-4.

6. Boukhari H. Hémopéricarde compliquant une ponction sternale (Hemopericardium complicating a sternal punction). Ann Fr Med Urgence 2012;2:193-5.

7. Jarry J, Lang-Landunski L, Perez JP, et al. Une complication grave de la ponction sternale: la plaie de l'aorte thoracique ascendante. Presse Med 2004;33:22-4.

8. Magaldi M, Hervias A, Perelló L, Fontanals J. Taponamiento cardiaco tras punctión esternal. Utilidad de la ecografía focussed assessment with sonography for trauma. Rev Esp Anestesiol Reanim. 2013 Jan 23. [Epub ahead of print].

9. Chavanis N, Frieh JP, Bougon D, Costache VS. I shouldn't be alive: bone marrow biopsy. Eur J Cardiothorac Surg 2013;43:653. 